\title{
Seismic Analysis of RC Elevated Rectangular Water Tank using Various Staging Patterns
}

\author{
M. Sai Ramya ${ }^{1}$ and J. Sandhya Rani ${ }^{2}$ \\ ${ }^{1}$ PG Scholar, CVR College of Engineering/Civil Engg. Department, Hyderabad, India. \\ Email: medisettysairamya950@gmail.com \\ ${ }^{2}$ Asst. Professor, CVR College of Engineering/Civil Engg. Department, Hyderabad, India. \\ Email: sandhyajaligama25@gmail.com
}

\begin{abstract}
Elevated water tanks are the structures of greater importance which are considered as the main lifeline elements. Many displeasing experiences have taken place earlier due to the damage and collapse of elevated water tanks due to the occurrence of earthquakes. The reason behind the damage is lack of providing proper supporting system to the water tank to withstand the dynamic loads and also due to improper selection of staging. The main objective of the present study is to evaluate the seismic response of elevated rectangular water tank with different staging patterns and different water level conditions (full, half and empty). Four types of bracing systems of elevated water tank such as normal bracing, diagonal bracing, $\mathrm{V}$ bracing, and cross bracing are considered for the analysis with various water level conditions. A total of 12 combinations were analysed and base shear, base moment and roof displacement for the fixed models were calculated with SAP2000 v 20.0.0 software using Response Spectrum Method (RSM) and results are presented.
\end{abstract}

Index Terms: Elevated rectangular water tank, Staging patterns, Water level conditions, SAP2000 version20, RSM.

\section{INTRODUCTION}

Water is a very important source like food and air for the existence of life. To make it available for common public, Government of India provided a substantial amount to the water supply project. Elevated water tank is a structure used to store water, which is supported by a tower. The crest of the tower provides required pressure to supply water. Therefore, it is constructed at an elevation to accommodate useful storage and also maintain sufficient pressure for the water distribution system [6]. During the high peak hours of the water system, the static potential reserved in the tank is used to provide the pressure in the water pipes and helps the pumping systems by maintaining the necessary water pressure without increasing pumping capacity. They also present enough water pressure for fire-fighting when the pumping systems are not sufficient to provide large amount of water needed for fire extinguishing.

During an earthquake, sudden release of energy from the Earth's crust takes place, due to which seismic waves propagates. Earthquakes causes shaking or displacement of the structures constructed on the surface of the earth, which leads to destruction of the property and can also cause loss of life. Industrial liquid storage tanks may contain highly poisonous and inflammable liquids. Therefore, it is very important to consider the safety of liquid storage tanks and these tanks should be made leak proof and there is a chance of leakage of these poisonous liquids during an earthquake.
Liquid storage tanks are primarily classified into two types:

a) Ground supported tanks and

b) Elevated tanks.

Elevated tanks depend on hydrostatic pressure induced by the altitude of water enabling the supply of water even during power interruptions. This feature of elevated water tanks proves more efficient during power interruption after the occurrence of severe earthquakes and also in the situations where pumping systems are unable to work which depend on electrical power.

Elevated water tanks are generally supported on reinforced concrete frame, steel frame, masonry pedestal or reinforced concrete pedestal. In the present study, the elevated water tank is supported on reinforced concrete pedestals.

\section{A. Scope of present study}

In the present work models of elevated rectangular water tank set in seismic zone-II with medium soil, the soil is analysed by a linear dynamic methodology using SAP2000. The scope of present study aims at analysis of elevated storage tank with different water level conditions and includes displacement, base shear, base moments for a given structure, and to seek out the variation of relative results.

\section{B. Objectives of present study}

The objectives of present study are as follows: a) The main objective of this study is to evaluate the seismic response of elevated water tank with different staging patterns and water level conditions (full, half and empty) by using response spectrum method

b) To study numerous responses like roof displacement, base shear, base moment etc.

\section{Types of Bracing Patterns}

In this study four types of bracing patterns are considered. They are normal, diagonal, cross, and $\mathrm{V}$ bracings [9] as shown in Figure 1, Figure 2, Figure 3 and Figure 4.
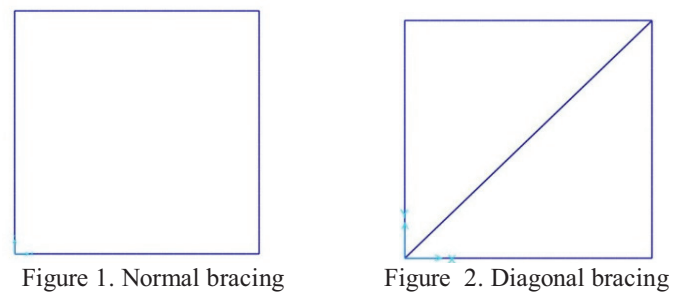


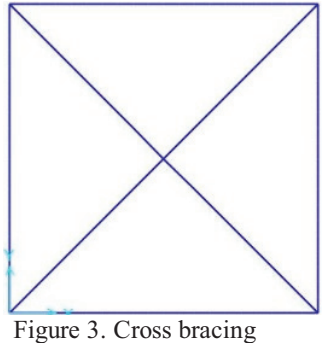

\section{LITERATURE REVIEW}

Some of the research works carried out since 2013 are presented below:

Pavan.S. Ekbote, Prof. Dr. Jagadish.G. Kori had discussed the Seismic behavior of RC Elevated Water Tank under different types of staging patterns. The main aim of this study is to understand the behaviour of supporting system which is more effective under different response spectrum method with SAP 2000 software. In this paper different supporting systems such as radial bracing and cross bracing have been taken and the Base shear, Over-turning moment, Bending Moment, Story displacement had been calculated and the results are stated. [1]

Varun Suchak, Assistant Professor Dipak Jivani (May 2014) had discussed the Seismic Performance of Elevated Tank Staging Patterns under Different Ground Motions. An attempt has been made in this paper to understand the behavior of supporting system which is more effective under different earthquake recorded ground motions. In this paper time history analysis is carried out for elevated tank with three types of staging pattern under different five earthquake ground motion records. [2]

Ankush N. Asati, Prof. Dr. Mahendra S.Kadu ( Aug 2014) had discussed the Seismic Investigation of RC Elevated Water Tank for Different Types of Staging Patterns. The seismic behavioural effect of elevated circular water tank is studied for constant capacity and constant number of columns; for various types of staging arrangement in plan, and variation in number of stages in elevation by using finite element method-based software SAP2000. [3]

Miss. Sonali M. Maidankar, Prof. G.D. Dhawale, Prof. S.G. Makarande (Jan.- 2015) had discussed the Seismic Analysis of Elevated Circular Water Tank using various Bracing Systems. The main aim of this study is to understand the behavior of different staging, under different loading conditions and strengthening the conventional type of staging, to give better performance during earthquake. For three different types of bracing systems, applied to the staging of elevated circular water tank for earthquake zones. Analysis is carried out using SAP2000 v15. [4]

Sudip Jha M.Tech, Cherukupally Rajesh, Associate proff. P. Srilakshmi (November 2015) had discussed the Behaviour of an Elevated Water Tank for Different Staging Patterns and Different Staging Heights. In this paper an extensive computational study has been conducted to find out the performance of elevated water tank under wind force. [5]
Sonali M. Pole, Asst. Professor. Amey R. Khedikar had done the Seismic Investigation of RC Elevated Water Tank for different Types of Staging Systems. The aim of this study is to understand the behaviour of different staging, under different loading conditions and strengthening the conventional type of staging, to give better performance during earthquake. This paper presents seismic analysis of elevated water tanks supported on different staging pattern with different tank storage capacities. [6]

J Visuvasam, J Simon, J S Packiaraj, R Agarwal, L Goyal and V Dhingra (2017) had discussed the Seismic response of elevated rectangular water tanks considering soil structure interaction. In this paper, the flexible base was provided as spring stiffness in order to consider the effect of soil properties on the seismic behaviour of water tanks. A linear time history earthquake analysis was performed using SAP2000. [7]

Mayank Gopal Manwani, Deepa P. Telang (May 2017) had discussed a Review on Seismic Analysis of Elevated Water Tank with Variations of H/D Ratio and Container Shape. In this study, Seismic forces acting on an Elevated water tank e.g. circular Tank and rectangular tank are studied with constant stagging height. [8]

\section{Methodology}

Earthquakes are caused due to ground vibration which imparts a non-linear lateral load on structure for a period of time. These seismic vibrations are unpredictable and are destructive events for the structures. Exact estimation of the seismic forces for the design of the seismic proof structure is practically impossible. When the natural frequency of the lateral load coincides with the natural frequency of the sloshing water inside the tank, it results in severe damage or failure of the structure. Seismic analysis is a group of structural analysis which describes the response of the structure to the earthquake. Seismic analysis is also applicable in structural design where earthquakes are extensive. The seismic analysis of a structure involves assessment of the earthquake forces acting at various levels of the structure during an earthquake and the effect of such forces on the behavior of the overall structure is also determined. The analysis is classified as static and dynamic in approach as per the code provisions.

Further, Structural analysis methods can be categorized into the following categories-

- Equivalent static analysis or Linear static analysis

- Response spectrum analysis or Linear dynamic analysis

- Pushover analysis or Non-linear static analysis

- Time history analysis or Non-linear dynamic analysis.

In the present study, response spectrum method of analysis is carried out.

\section{A.Response Spectrum Method}

Response spectrum method is considered as a linear dynamic analysis. This method allows the multiple modes of response of a building to be taken into consideration (in the frequency domain) the considerable effect of any mode 
except the fundamental mode on the response of the structure is considered. In this methodology, the response of Multi Degree of Freedom (MDOF) is expressed as the superposition of every Single Degree of Freedom (SDOF) system, that is then combined to calculate the whole response. This can be needed in many building codes for all apart from terribly simple or terribly complicated structures. Computer analysis is used to confirm these modes for a structure. For each mode, a response is read from the planning spectrum, based on the model frequency and also the model mass and they are then combined to produce an estimate of the overall response of the structure.

\section{Problem Description}

In the present study four types of arrangements have been considered i.e. normal, diagonal, cross and $\mathrm{V}$ bracings for fixed base models. An elevated rectangular water tank of $1,08,000$ liters capacity is supported on RC staging of 9 columns with horizontal bracings of $200 \times 200 \mathrm{~mm}$ at three levels. Grade of concrete and steel are M30 and Fe415, respectively. Density of concrete is $25 \mathrm{kN} / \mathrm{m}^{3}$. The structural software SAP 2000 v20 is used to model the elevated rectangular water tank using response spectrum method and models are shown in Figure 5. Other dimensions of the elevated tanks are illustrated in the Table-I.

TABLE I.

PARAMETERS OF E.W.T

\begin{tabular}{|c|c|}
\hline Parameters & Values \\
\hline Capacity of tank & 108000 lit \\
\hline Density of concrete & $25 \mathrm{kN} / \mathrm{m}^{3}$ \\
\hline Grade of steel & $\mathrm{Fe} 415$ \\
\hline Grade of concrete & M30 \\
\hline No. of columns & 8 \\
\hline Height of staging & 20 \\
\hline Staging levels & 3 \\
\hline Size of beam & $300 \mathrm{mmx} 450 \mathrm{~mm}$ \\
\hline Size of braces & $200 \mathrm{~mm} \times 200 \mathrm{~mm}$ \\
\hline Size of columns & $600 \mathrm{mmx} 600 \mathrm{~mm}$ \\
\hline Slab size & $150 \mathrm{~mm}$ \\
\hline Wall size & $200 \mathrm{~mm}$ \\
\hline Height of tank & $3 \mathrm{~m}$ \\
\hline Response reduction factor & 5 \\
\hline Zone & $\mathrm{V}$ \\
\hline Seismic zone factor & 0.36 \\
\hline Importance factor & 1 \\
\hline
\end{tabular}

\section{Elevated Water Tank Models}

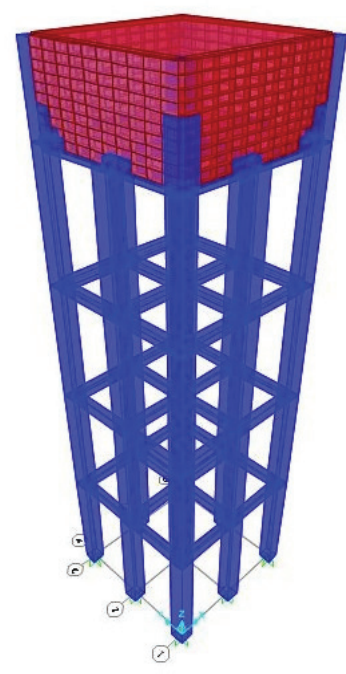

A) Model

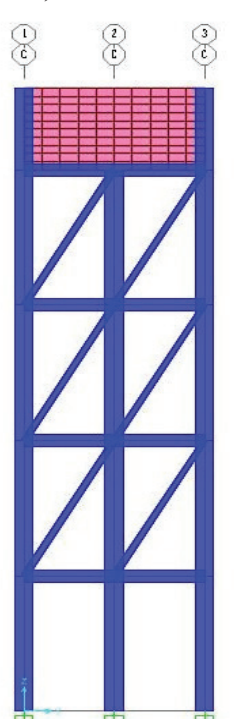

C) Cross bracing.

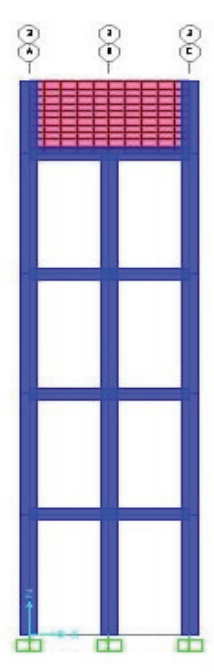

B) Normal bracing

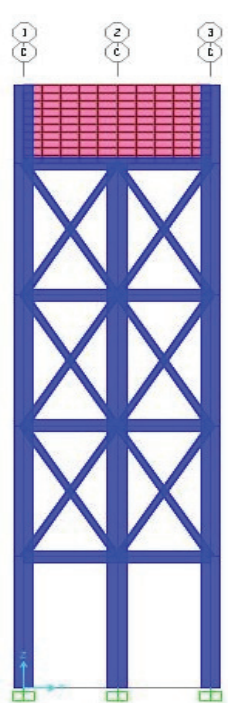

D) Diagonal bracing

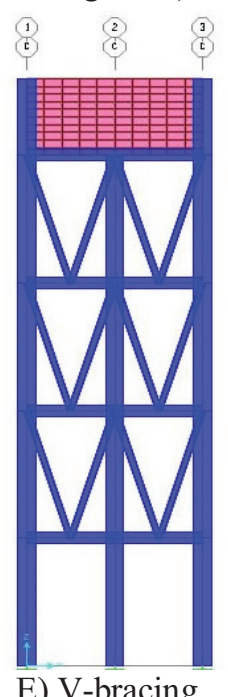

Figure 5. Models of E.W.T 
VII. RESUlts

Response spectrum analysis is carried out using SAP 2000 for fixed base models. The results obtained for elevated water tank with different water level conditions and various staging patterns are Roof displacement (Figure 6), Base shear (Figure 7) and Base moment (Figure 8). Subsequent discussions are made about the results obtained.

TABLE II.

ROOF DisPlacement For DifFERENT STAGING PATTERnS

\begin{tabular}{|c|r|r|r|l|}
\hline \multirow{2}{*}{$\begin{array}{c}\text { Fluid } \\
\text { level } \\
\text { Conditions }\end{array}$} & \multicolumn{4}{|c|}{ ROOF DISPLACEMENT (mm) } \\
\cline { 2 - 5 } & $\begin{array}{c}\text { Normal } \\
\text { bracing }\end{array}$ & bracing & $\begin{array}{l}\text { Diagonal } \\
\text { bracing }\end{array}$ & $\begin{array}{l}\text { Cross } \\
\text { bracing }\end{array}$ \\
\cline { 2 - 5 } & 9.9095 & 5.7987 & 3.2869 & 3.9202 \\
\hline Empty & 12.166 & 4.4822 & 2.651 & 2.6283 \\
\hline $\begin{array}{c}\text { Half } \\
\text { Full }\end{array}$ & 25.187 & 5.6618 & 3.6243 & 3.3199 \\
\hline Full & & & & \\
\hline
\end{tabular}

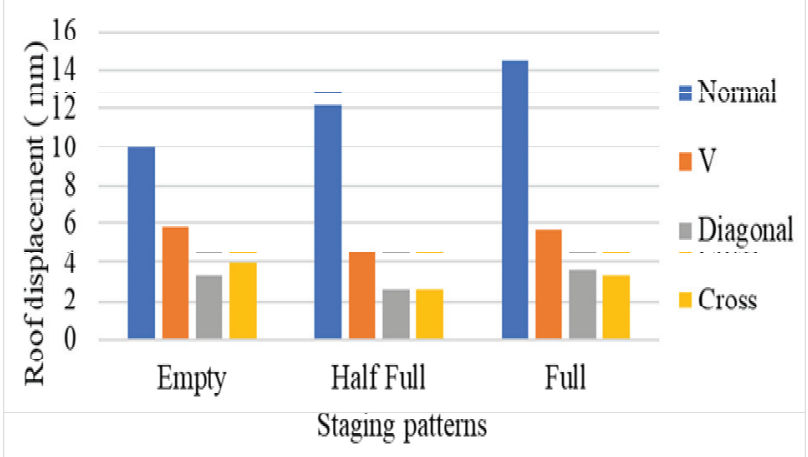

Figure 6. Roof displacement (in $\mathrm{mm}$ ) for different staging patterns

TABLE III

BASE SHEAR For DifFERENT StAGING PATTERnS

\begin{tabular}{|c|c|c|c|c|}
\hline \multirow{2}{*}{ Fluid } & \multicolumn{4}{|c|}{ BASE SHEAR FOR DIFFERENT STAGING PATTERNS } \\
\cline { 2 - 5 } level & \multicolumn{4}{|c|}{ Bracing types } \\
\cline { 2 - 5 } & Normal & V & Diagonal & Cross \\
\hline Empty & 175.136 & 233.239 & 160.264 & 224.898 \\
\hline $\begin{array}{c}\text { Half } \\
\text { Full }\end{array}$ & 263.879 & 242.427 & 165.399 & 233.751 \\
\hline Full & 318.406 & 281.257 & 196.331 & 244.758 \\
\hline
\end{tabular}

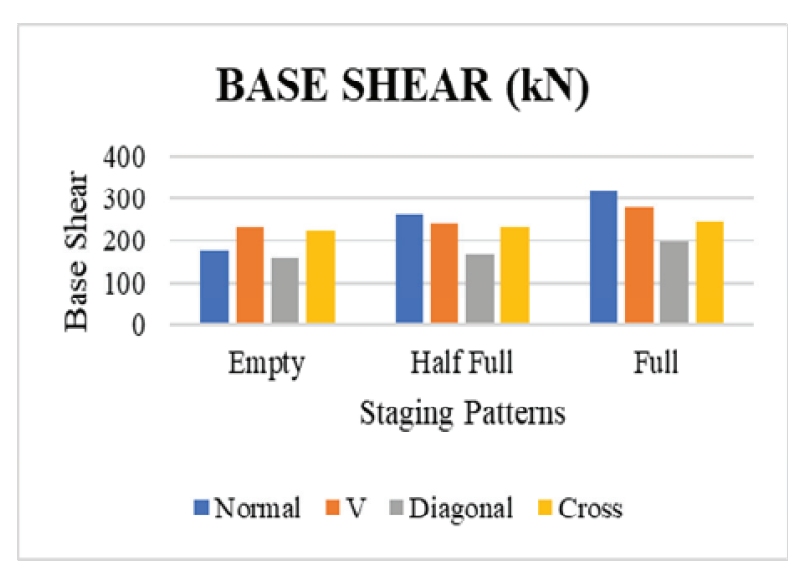

Figure 7. Base shear (in $\mathrm{KN}$ ) for different staging patterns

TABLE IV.

Base MOMEnT For DifFERENT STAGing PATTERnS

\begin{tabular}{|c|c|c|l|l|}
\hline \multirow{2}{*}{ Fluid } & \multicolumn{4}{|c|}{ BASE MOMENT Mx (kN-m) } \\
\cline { 2 - 5 } & \multicolumn{4}{|c|}{ Bracing types } \\
\cline { 2 - 5 } condition & Normal & V & Diagonal & Cross \\
\hline Empty & 2976.95 & 3027.82 & 2184.54 & 2772.63 \\
\hline Half Full & 3709.19 & 3828.75 & 2629.38 & 3502.29 \\
\hline Full & 4403.86 & 3828.83 & 2759.6 & 3923.9 \\
\hline
\end{tabular}

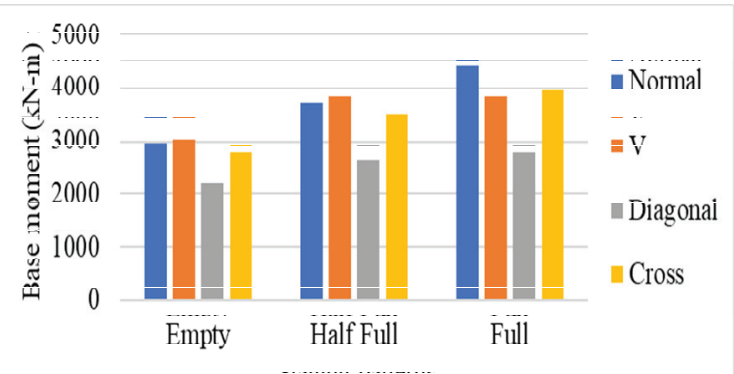

Staging patterns

Figure 8. Base moment (kN-m) for different staging patterns

\section{Conclusions}

a) It is observed that diagonal bracing provide minimum value of lateral displacement for empty tank, half tank and full tank condition.

b) The diagonal bracings are more effective compared to the other type of bracings of bracings for empty, half and full tank conditions.

c) As the water level with the elevated tank increases from empty to half and full, the displacement of water tank also increases gradually from $9.1 \mathrm{~mm}$ to $14 \mathrm{~mm}$.

d) Base shear will increase as the capacity of water increases. It is observed that the capacity of water 
tank will increase from empty tank to full tank, then the Base shear will also increase from $175 \mathrm{kN}$ to $318 \mathrm{KN}$.

e) It is observed that diagonal bracing provides minimum value of Base shear for empty, half and full tank condition.

f) Base moment will increase as the capacity of water increases. It is observed that as the capacity of water increases from empty tank to full tank the Base moment will also increase from $525 \mathrm{kN}-\mathrm{m}$ to $955 \mathrm{kN}-\mathrm{m}$.

g) Its observed that diagonal bracing provide minimum value of Base moment for empty, half and full tank condition.

\section{SCOPE For Further WORK}

a) The further scope of the work is to consider water tanks with varying capacities and shaft geometries in order to verify the effects of these parameters on the nonlinear response of such structures.

b) The application of seismic isolators or energy dissipaters can be investigated in controlling the seismic response of RC shafts.

\section{REFERENCES}

[1] Pavan.S.Ekbote, Jagadish.G.Kori, "Seismic Behaviour of RC Elevated Water Tank under Different Types of Staging Patterns" Journal of E ngineering, Computers \& Applied Sciences (JEC\&AS), Volume-2, No.8, August 2013.

[2] Varun Suchak, Dipak Jivani, "Seismic Performance of Elevated Tank Staging Patterns under Different Ground Motions", Volume- 1, Issue -6, May 2014.

[3] Ankush.N.Asati, Mahendra.S.Kadu,"Seismic investigation of RC Elevated Water Tank for Different Types of Staging Patterns", (IJETT) -Volume 14 Number 1 - Aug 2014.

[4] Ms.Sonali. M.Maidankar, G.D. Dhawale,S.G. Makarande, "Seismic Analysis of Elevated Circular Water Tank using various Bracing Systems", (IJAERS) - Volume-2, Issue-1, Jan.- 2015.

[5] Sudip Jha, Cherukupally Rajesh, Sri Lakshmi, "Behaviour of an Elevated Water Tank for Different Staging Patterns and Different Staging Heights", IJMETMR, August 2015.

[6] Sonali.M.Pole, Amey.R.Khedikar, "Seismic Investigation of RC Elevated Water Tank for different Types of Staging Systems", Volume- 6, Issue 7, July 2017.

[7] J Visuvasam, J Simon, J S Packiaraj, R Agarwal, L Goyal and V Dhingra, "Seismic response of elevated rectangular water tanks considering soil structure interaction", IOP Conf. Series: Materials Science and Engineering 263 (2017).

[8] Mayank Gopal Manwani, Deepa P. Telang, "Review on Seismic Analysis of Elevated Water Tank with Variations of H/D Ratio and Container Shape", IJCSMC, Vol. 6, Issue. 5, May 2017, pg.202 - 208.

[9] Prashant A Bansode, V. P. Datye, "Seismic Analysis of Elevated Water Tank with Different Staging", Journal of Geotechnical Studies Volume- 3 Issue 1. 